\title{
Cerebrospinal fluid biomarkers in Alzheimer's disease, vascular dementia and ischemic stroke patients: a critical analysis
}

\author{
Lisa Kaerst • Andre Kuhlmann • Dirk Wedekind • \\ Katharina Stoeck $\cdot$ Peter Lange $\cdot$ Inga Zerr
}

Received: 18 April 2013/Revised: 11 June 2013/Accepted: 13 June 2013/Published online: 23 July 2013

(C) The Author(s) 2013. This article is published with open access at Springerlink.com

\begin{abstract}
Vascular factors are thought to contribute to the development of disease pathology in neurodegenerative dementia such as Alzheimer's disease (AD). Another entity, called vascular dementia $(\mathrm{VaD})$, comprises a less defined group of dementia patients having various vascular diseases that especially emerge in the elderly population and require valid options for examination and differential diagnosis. In the context of a retrospective study, we analyzed the cerebrospinal fluid (CSF) biomarkers t-tau, p-tau and $\mathrm{A} \beta 42$ of a total of 131 patients with $\mathrm{AD}(n=47)$, mild cognitive impairment (MCI) $(n=22), \mathrm{VaD}(n=44)$ and stroke $(n=18)$. We found a remarkable alteration in CSF biomarker profile in $\mathrm{AD}, \mathrm{VaD}$ and in acute ischemic events. CSF profile in AD patients was altered in a very similar way as in stroke patients, without statistical differences. In stroke, increase depend largely on size and duration after the initial event. Total tau levels were useful to differ between $\mathrm{VaD}$ and stroke. $\mathrm{A} \beta 42$ decreased in a similar way in $\mathrm{AD}, \mathrm{VaD}$ and stroke and had a trend to lower levels in MCI but not in controls.
\end{abstract}

Keywords CSF $\cdot$ Biomarkers $\cdot$ A $~ \cdot$ Tau $\cdot$ Alzheimer's disease $\cdot$ Vascular dementia $\cdot$ Stroke

L. Kaerst · A. Kuhlmann · K. Stoeck · P. Lange · I. Zerr ( $₫)$ Department of Neurology, Clinical Dementia Center, University Medical Center, Georg August University Göttingen, Göttingen, Germany

e-mail: epicjd@med.uni-goettingen.de

D. Wedekind

Department of Psychiatry and Psychotherapy, Georg August

University Göttingen, Göttingen, Germany

\section{Introduction}

Dementias due to neurodegenerative diseases are frequent in the elderly population but at the same time, vascular pathology is prevalent in the same age groups, too. Vascular factors contribute to $A D$ pathology and perivascular $A B$ amyloid deposits have been observed in both $\mathrm{AD}$ and vascular dementia $(\mathrm{VaD})$. The correct identification of patients with dementia might be hampered by the possible overlap with stroke events. An ischemic event will significantly lead into the aggravation of the clinical symptoms or might even trigger clinically yet unapparent disease, which might unmask after a strategic stroke. These interactions are not well understood and only limited information is available in the literature how CSF biomarkers which are used in dementia diagnosis might be influenced by ischemic events. If so, a careful exclusion of acute ischemic events will be necessary to support the common dementia diagnosis in elderly persons, and clinicians should take into account the possibility of a silent stroke [1]. We identified a series of patients with acute ischemic events as detected by MRI in combination with a poor performance in neuropsychological tests. In this study, we performed an analysis to see if CSF biomarkers might be altered in the same way in dementia and after stroke.

\section{Methods}

Patient's data collection and analysis

Patients having different forms of neurological diseases who underwent lumbar puncture for diagnostic purposes which included CSF dementia marker profile, were analyzed. We selected data from those with a clinical 
diagnosis of $\mathrm{AD}(n=47)$, mild cognitive impairment (MCI) $(n=22), \operatorname{VaD}(n=44)$ and stroke $(n=18$, including three patients with previously diagnosed AD and a recent stroke) for further analysis (Table 1). For statistical analysis we considered all 18 patients with stroke, including three patients with $\mathrm{AD}$ and stroke.

All tests were performed in the Neurochemistry Laboratory at the Department of Neurology, University Medical School, Göttingen. CSF was obtained by lumbar puncture and processed immediately. CSF was examined for standard parameters such as cell count, proteins and immunoglobulins, and tau, phosphorylated tau and amyloid- $\beta_{1-42}$ according to established protocols. CSF tau protein was quantitatively analysed using a commercially available ELISA kit according to manufacturer's instruction (INNOTEST $^{\circledR}$ hTAU Ag, Innogenetics). Human tau, phosphorylated at Thr181 (phosphorylated tau) was measured quantitatively with a commercially available ELISA kit [INNOTEST $^{\circledR}$ PHOSPHO-TAU(181P), Innogenetics]. A pathological elevated phosphorylated tau level was considered at $>61 \mathrm{pg} / \mathrm{ml}$ according to manufacturer's instruction, aimed at the diagnosis of Alzheimer's disease. Amyloid $\beta_{1-42}$ was detected with a commercially available ELISA kit [INNOTEST ${ }^{\circledR} \quad \beta-\quad \operatorname{AMYLOID}(1-42)$
Innogenetics] for quantitative analysis. A pathological decreased amyloid $\beta_{1-42}$ assay was considered at $<450 \mathrm{pg} /$ $\mathrm{ml}$ according to manufacturer's instruction. Amyloid $\beta_{1-40}$ was detected by ELISA (Genetics Company, Schlieren, Switzerland). The study was approved by the local ethics committee (16 July 2010). The diagnoses of the patients were based on the following criteria:

AD The diagnosis was based on recent criteria ICD10 definition for Alzheimer's disease (F.00 G.30)

MCI The diagnosis was based on neuropsychological evaluation (decline in MMSE)

Stroke The diagnosis was based on clinical syndrome and neuroimaging (CT, MRI)

$\mathrm{VaD}$ The diagnosis was based on ICD 10 definition (F 01)

Statistical evaluation

The ANOVA test (Levene, Bonferroni and Tamhane T2) and Kruskal-Wallis test were used to compare the values. Values of $p<0.05$ were considered to be significant. The BOX-Plot was used for the graph. The statistical analyses were done using IBM SPSS Statistics 19.
Table 1 Clinical characteristics of patients included in the study

0 not determined, 1 still independent, 2 need of care, 3 high need of care, 4 exitus

$*$ controls $=$ patients with depression and other nonneurological diseases

$* *$ age $=$ age at CSF analysis *** corresponds to the period passed by since the first diagnosis of disease **** number of patients dedicated to a certain degree of self-dependence determined by MMSE, DemTect and their symptoms

\begin{tabular}{|c|c|c|c|c|c|}
\hline Diagnosis & $n$ & Age in years** & Gender m:f & Duration in months $* * *$ & Severity**** \\
\hline \multicolumn{6}{|l|}{ Control* } \\
\hline Arithmetic mean & 22 & 58.9 & $10: 11$ & $\begin{array}{l}(n=9) \\
84.8\end{array}$ & \\
\hline Min & & 47 & & 9 & \\
\hline Max & & 72 & & 240 & \\
\hline \multicolumn{6}{|l|}{ MCI } \\
\hline Arithmetic mean & 22 & 69.8 & $14: 8$ & $\begin{array}{l}(n=11) \\
22.5\end{array}$ & $\begin{array}{l}0=2 \\
1=19\end{array}$ \\
\hline Min & & 55 & & 3 & $2=1$ \\
\hline Max & & 86 & & 60 & \\
\hline \multicolumn{6}{|l|}{$\mathrm{AD}$} \\
\hline Arithmetic mean & 47 & 70.5 & $11: 36$ & $\begin{array}{l}(n=32) \\
25.1\end{array}$ & $\begin{array}{l}0=1 \\
1=18\end{array}$ \\
\hline Min & & 32 & & 1 & $2=20$ \\
\hline Max & & 87 & & 84 & $3=8$ \\
\hline \multicolumn{6}{|l|}{$\mathrm{VaD}$} \\
\hline Arithmetic mean & 44 & 73.9 & $21: 23$ & $\begin{array}{l}(n=22) \\
26.7\end{array}$ & $\begin{array}{l}1=26 \\
2=13\end{array}$ \\
\hline Min & & 53 & & 2 & $3=5$ \\
\hline Max & & 86 & & 108 & \\
\hline \multicolumn{6}{|l|}{ Stroke } \\
\hline Arithmetic mean & 18 & 72.6 & $10: 8$ & $\begin{array}{l}(n=12) \\
1.4\end{array}$ & $\begin{array}{l}1=6 \\
2=7\end{array}$ \\
\hline Min & & 51 & & 0 & $3=4$ \\
\hline Max & & 86 & & 3 & $4=1$ \\
\hline
\end{tabular}




\section{Results}

We report similarities in the CSF profiles of those with AD and those who underwent lumbar puncture after stroke. Apart from their different sizes and the distribution of gender, both groups are especially comparable concerning age (AD arithmetic mean of 70.5 years, stroke 72.6 years) (Tables 1 and 2). Increased tau and decreased Aß42 were similar in patients with AD and in those after stroke. The highest total-tau levels were found in the stroke group (arithmetic mean $516 \mathrm{pg} / \mathrm{ml}$, median $468 \mathrm{pg} / \mathrm{ml}$ ). The highest p-tau levels were seen in AD patients, followed by MCI, stroke and VD. Also Aß40 levels were low in AD and stroke patients (Table 2; Fig. 1).

T-tau levels of AD-patients (arithmetic mean $391 \mathrm{pg} / \mathrm{ml}$ ) showed less variation than in stroke (arithmetic mean $516 \mathrm{pg} / \mathrm{ml}$ ). In $\mathrm{VaD}$, t-tau levels were significantly lower than in stroke patients (arithmetic mean $302 \mathrm{pg} / \mathrm{ml}$ ) $(p=0.018)$. There were no significant differences between stroke (arithmetic mean $62 \mathrm{pg} / \mathrm{ml}$ ) and AD (arithmetic mean $74 \mathrm{pg} / \mathrm{ml}), p=0.465, \mathrm{AD}$ and MCI (arithmetic mean $65 \mathrm{pg}$ / $\mathrm{ml}), p=1.0$ and $\mathrm{AD}$ and $\mathrm{VaD}$ (arithmetic mean $58 \mathrm{pg} / \mathrm{ml}$ ), $p=0.579$. The highest values of $\mathrm{p}$-tau were found in $\mathrm{AD}$, followed by MCI, similar to stroke and finally $\mathrm{VaD}$ (Table 2). As a biomarker, p-tau was not useful to distinguish between any of the groups, although higher levels are observed in AD.

For $\mathrm{A} ß 42$, there was a significant difference between AD (arithmetic mean $580 \mathrm{pg} / \mathrm{ml}$ ) and MCI (arithmetic mean $856 \mathrm{pg} / \mathrm{ml}), p=0.015$, as well as between MCI and stroke (arithmetic mean $553 \mathrm{pg} / \mathrm{ml}$ ), $p=0.022$. No difference was observed for $\mathrm{AD}$ and stroke $(p=0.999)$, which points out the similarity between CSF Aß42 levels in both. Similar findings were obtained for Aß42 in stroke and $\mathrm{VaD}$ (arithmetic mean $701 \mathrm{pg} / \mathrm{ml}$ ), $p=0.341$. Aß42 levels in $\mathrm{AD}$ and $\mathrm{VaD}$ were in the same range $(p=0.247)$.

No significant differences between the groups were found when we calculated the $\mathrm{A} \beta$ ratio $[p$-values between 0.757 and 1.0, proof for homogeneity of variances among the single groups (data not shown)].

In this study we were specifically interested in total tau levels in patients after stroke. Because the time of the lumbar puncture varied from the day of ischemic event up to several weeks after and because the sizes and localization of the lesion generally affects the CSF protein profile (middle brain, thalamus, capsula interna and media total infarction), the tau values vary to a great extend (Fig. 2). The tau levels were even still increased within the period over 1 month, reaching values of $1,300 \mathrm{pg} / \mathrm{ml}$ in one patient.

We stratified the single patients to different subgroups considering the infarction size, time of lumbar puncture related to the time of stroke. The lowest levels were observed in stroke patients with an acute and limited brain volume damage, such as pons ischemia ( $n=2$, tau 144 and $121 \mathrm{pg} / \mathrm{ml}$ ), while the highest were observed in a patient 1 month after a media infarction (tau 1,300 pg/ml). As final result, we found highest tau levels in patients with large stroke areas and subacute stage (media total infarction and multiple strokes, $n=3$, arithmetic mean $986 \mathrm{pg} /$
Table 2 Cerebrospinal fluid levels of tau, p-tau, $A \beta_{1-42}$ and $\mathrm{A} \beta_{1-40}$ stratified by disease type

* controls: patients with depression

** $\mathrm{VaD}$ without recent stroke

\begin{tabular}{|c|c|c|c|c|c|}
\hline $\begin{array}{l}\text { CSF } \\
\mathrm{pg} / \mathrm{ml}\end{array}$ & $\begin{array}{l}\text { Controls* } \\
\text { Mean (SD) } \\
\text { Median } \\
(\min -\max ) \\
n\end{array}$ & $\begin{array}{l}\text { MCI } \\
\text { Mean (SD) } \\
\text { Median } \\
(\min -\max ) \\
n\end{array}$ & $\begin{array}{l}\text { AD } \\
\text { Mean (SD) } \\
\text { Median } \\
(\text { min-max) } \\
n\end{array}$ & $\begin{array}{l}\text { VaD** } \\
\text { Mean (SD) } \\
\text { Median } \\
\text { (min-max) } \\
n\end{array}$ & $\begin{array}{l}\text { Stroke } \\
\text { Mean (SD) } \\
\text { Median } \\
(\min -\max ) \\
n\end{array}$ \\
\hline \multirow[t]{3}{*}{ Tau } & $131(58)$ & $311(243)$ & $391(232)$ & $302(252)$ & $516(317)$ \\
\hline & $\begin{array}{l}126 \\
(75-253)\end{array}$ & $\begin{array}{l}200.5 \\
(75-1,080)\end{array}$ & $\begin{array}{l}339 \\
(75-910)\end{array}$ & $\begin{array}{l}258 \\
(75-1,145)\end{array}$ & $\begin{array}{l}468 \\
(121-1,300)\end{array}$ \\
\hline & 21 & 22 & 47 & 44 & 18 \\
\hline \multirow[t]{3}{*}{ p-tau } & $33(15)$ & $65(35)$ & $74(44)$ & $58(34)$ & $62(36)$ \\
\hline & $\begin{array}{l}30 \\
(2-52)\end{array}$ & $\begin{array}{l}57.5 \\
(16-156)\end{array}$ & $\begin{array}{l}70 \\
(20-243)\end{array}$ & $\begin{array}{l}55 \\
(21-148)\end{array}$ & $\begin{array}{l}56 \\
(15-111)\end{array}$ \\
\hline & 10 & 14 & 31 & 21 & 7 \\
\hline \multirow[t]{3}{*}{$\mathrm{A} ß 42$} & 927 (164) & $856(362)$ & $580(211)$ & 701 (341) & $553(245)$ \\
\hline & $\begin{array}{l}942 \\
(476-1,685)\end{array}$ & $\begin{array}{l}825.5 \\
(256-1,650)\end{array}$ & $\begin{array}{l}537.5 \\
(246-1,026)\end{array}$ & $\begin{array}{l}608 \\
(251-1,775)\end{array}$ & $\begin{array}{l}443 \\
(243-1,002)\end{array}$ \\
\hline & 21 & 22 & 46 & 44 & 17 \\
\hline \multirow[t]{2}{*}{$\mathrm{A} ß 40$} & $\begin{array}{l}6,421(2,045) \\
5,885.5 \\
(4,288-11,031)\end{array}$ & $\begin{array}{l}9,437(3,081) \\
9,830.5 \\
(3,321-13,729)\end{array}$ & $\begin{array}{l}7,062(1,890) \\
6,843 \\
(3,604-11,257)\end{array}$ & $\begin{array}{l}9,964(5,639) \\
8,276 \\
(4,493-29,786)\end{array}$ & $\begin{array}{l}6,258(2,328) \\
5,846 \\
(3,356-9,599)\end{array}$ \\
\hline & 12 & 12 & 24 & 20 & 5 \\
\hline
\end{tabular}



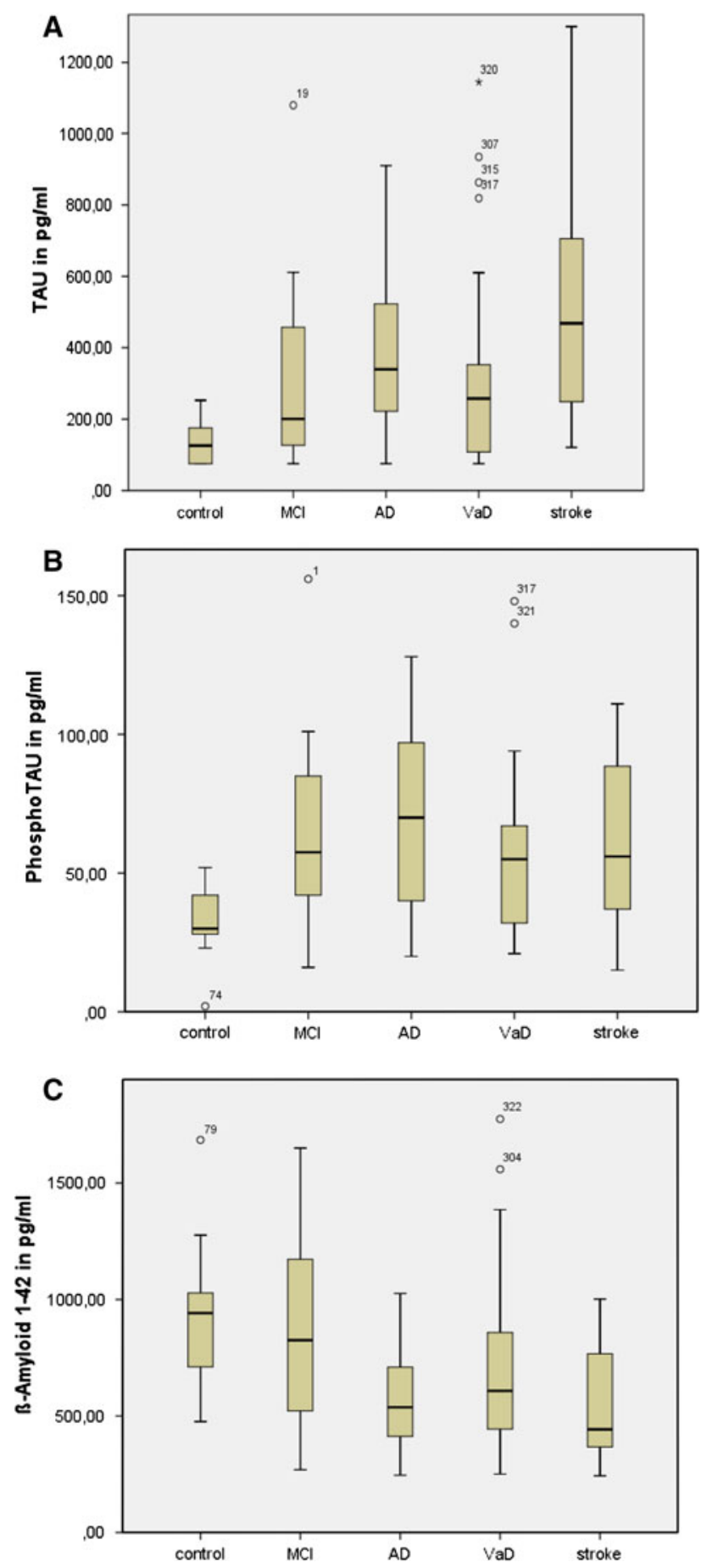

Fig. 1 a [t-Tau] CSF levels across the groups b [p-Tau] CSF levels across the groups $\mathbf{c}$ [Aß42] CSF levels across the groups

$\mathrm{ml}$ ), followed by those patients with similar location but in acute stage $(n=4$, arithmetic mean $510 \mathrm{pg} / \mathrm{ml})$, followed by those with only limited infarction size $(n=2$, arithmetic mean $132.5 \mathrm{pg} / \mathrm{ml}$ ). Of importance, even small infarct areas led into increased CSF tau levels, especially several days after the stroke.

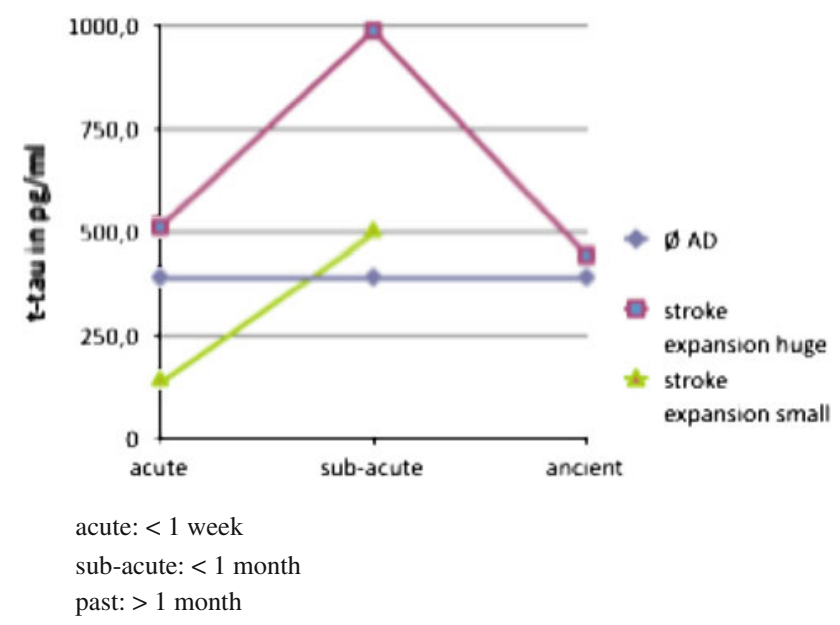

Fig. 2 Tau-values in $\mathrm{pg} / \mathrm{ml}$ after stroke defined by the size of damage and time point after the event

\section{Discussion}

The CSF analysis offers an excellent opportunity to detect early signs of neuronal degeneration and this has been widely used for $\mathrm{AD}$ and other dementia disorders. However, for correct interpretation, information on potential confounding factors is extremely important. Thus, we studied CSF alterations in CSF marker profiles of commonly used $\mathrm{AD}$ biomarkers in patients with $\mathrm{AD}, \mathrm{VaD}$ and stroke.

Increased values of tau and a decrease of $\mathrm{A} B 42$ were detected in $\mathrm{AD}$ in a similar manner as in $\mathrm{VaD}$ and acute ischemic events. With special regard to total tau, which is known as an indicator of neuronal damage and discussed to be specifically altered in $\mathrm{AD}$, an increase after stroke was not expected to this degree. In our literature research, we found only limited data dealing with CSF biomarkers after stroke, all of them well in line with results obtained here [2-5]. Tau was described to be significantly increased at day 2-3 (179\%), showing a peak after 1 week $(257 \%)$ and after 3 weeks (425\%), normalizing not until 3-5 month $(140 \%)$. No significant alteration of p-tau was reported.

For the distinction between $\mathrm{VaD}$ and $\mathrm{AD}, \mathrm{CSF}$ proteins were found to be more altered in $A D$, such as $A ß 42$ decrease and tau increase, especially phosphorylated forms (Table 2) [6-8]. According to the literature, to differentiate $\mathrm{AD}$ from $\mathrm{VaD}$, a combination of all three is recommended [9]. With special regard to $\mathrm{AD}$, a huge amount of data was published. One important aspect is $\mathrm{MCI}$ and its progression to $\mathrm{AD}$, which can potentially be predicted with the help of CSF profile [5, 10, 11]. Apparently those MCI patients with a more $\mathrm{AD}$-like $\mathrm{CSF}$ profile progress to $\mathrm{AD}$ in a shorter period of time, mostly showing low $\mathrm{A} \beta 42$ and high tau levels $[12,13]$. Because CSF biomarkers are already altered very early, there is the possibility to detect $\mathrm{AD}$ 
patients at risk or at very early stages. More precisely, Amyloid-peptide burden and changes in APP metabolism are altered at first up to 10 years before clinical symptoms. Tau proteins are supposed to be rather late markers [14].

The pathogenetic basis for our findings is not clear. CSF $\mathrm{A} \beta 42$ values are supposed to predict disease progression in $\mathrm{AD}$, but can be altered in $\mathrm{VaD}$, too. Up to now studies have mostly focused either on $\mathrm{AD}$ or on stroke and directly comparative analysis is rarely given. Similar to AD, imbalances concerning the total cleavage of APP, with tendencies towards accumulation to amyloid plaques, was reported in $\mathrm{VaD}$. Analogies between cognitive decline in patients after stroke with or without cerebrovascular pathologies prior to this can be seen in comparison to amyloid impact in AD [15].

Total tau might reflect the degree of neuronal damage after ischemia [3, 4]. CSF samples taken immediately after stroke, some days up to several weeks after stroke document an increase of t-tau with a peak after 1 week and a renormalization 3-5 months later [4]. The level of tau alteration depends on stroke size as well as on time passed since the event [3].

Neuronal apoptosis caused by ischemia is supposed to lead into hyperphosphorylation of tau, and p-tau is not increased directly after stroke [16]. Moreover, as a biomarker it is more useful for $\mathrm{AD}$ diagnosis but can be altered in the context of a chronic process like $\mathrm{VaD}$ [17]. Whether it can be considered as a new therapeutic target that should be regulated after ischemia and reperfusion process, remains to be determined [18].

Some research has been done using serum in patients after stroke and recently also in AD. Blood samples are of special research interests, because they are much easier to obtain and the analyses can be done sequentially. Increased serum tau was detected in $48 \%$ stroke patients. Those patients with detectable serum tau developed more severe neurological deficits [19-21]. Some other biomarkers were supposed to reflect processes of oxidative stress and inflammation followed by blood-brain barrier dysfunction after cerebral hypoxia. Acute-phase proteins like CRP and NSE were analyzed, too. A larger review concentrated on processes after ischemic brain injury, inflammatory processes contributing to neurodegeneration or by the ischemic event itself [16]. Amyloid balance is supposed to be hampered because of the down-regulation of $\alpha$-secretase resulting into the non-amyloidogenic pathway of total cleaving of APP, but accumulating soluble neurotoxic amyloid peptides via striking the second pathway using $\beta$ and $\gamma$-secretases. This explains the finding of AD-like pattern in rodents, starting some days after ischemia-an increase of $200 \%$ of APP in the penumbra on the seventh day post-stroke is described up to 1 year after the event [16]. It also raises the question of the cause of progressive cognitive decline following stroke, inflammatory or degenerative processes.

A striking overlap is found in $\mathrm{VaD}$ and $\mathrm{AD}$, such as hypertension, hyperlipidemia, diabetes mellitus and white matter changes subsequently lead into $\mathrm{VaD}$ on one hand; on the other hand patients with $\mathrm{AD}$ showed more often large vessel abnormalities, like carotid artery stenosis, carotid intimal-medial thinning and bilateral present carotid plaques. Prevalence of cardiovascular risk factors, atrial fibrillation, vessel stiffness and microinfarction increase with age and as result cognitive impairment is not distinctly due to $\mathrm{AD}$ or microvascular brain damage alone, rather than a mixture of both [22].

As a drawback of our study the deviation of our control group concerning age has to be mentioned (arithmetic mean 58.9 years). Being around one decade younger than $\mathrm{AD}$ or stroke patients with less developed age related changes of the vascular system or degenerative processes, their CSF analysis is expected to show less affected values of the proteins a priori. A control group with more similar age in comparison with the rest would have been more significant; however, since white matter lesions are common in the elderly, such a cohort will be difficult to obtain.

\section{Conclusions}

There is a clear importance to keep in mind the possibility of stroke and vascular degenerative processes, which might lead to increased tau and decreased Aß42 in CSF in a similar manner as in AD. Based on CSF biomarker analysis alone, we could not distinguish stroke from $\mathrm{AD}$ patients, since CSF alterations of $\mathrm{t}$-tau, $\mathrm{p}$-tau and Aß42 levels did not differ across groups. Because of its high incidence in elderly population, ischemic events have to be considered in the interpretation of given pathologic CSF profile with increased CSF tau, p-tau and decreased Aß42 levels.

Our conclusions based on our observations reported here are:

1. Ischemic events detected in neuroimaging can cause a pathological CSF profile which resembles those obtained in neurodegenerative dementia/AD

2. A follow-up examination of the biomarkers after several months might be necessary to exclude underlying dementia via normalized CSF profile

3. Patients suffering from stroke show distinct alterations of pathological CSF profile, especially an increase of T-tau

4. In differential diagnosis of cognitive decline after stroke, the pathological biomarker profile can be caused by the ischemic event itself and not by the neurodegeneration alone 
Acknowledgments The study was performed within the recently established Clinical Dementia Center at the University Medical School and was partly supported by grants from the JPND program [DEMTEST (Biomarker based diagnosis of rapid progressive dementias-optimisation of diagnostic protocols, 01ED1201A)] and from the Federal Ministry of Education and Research grant within the German Network for Degenerative Dementia, KNDD-2, 2011-2013, Determinants for disease progression in $\mathrm{AD}$.

Conflicts of interest All authors disclose any actual or potential conflicts of interest including any financial, personal or other relationships with other people or organisation within 3 years of beginning the work

Ethical standard All human studies must state that they have been approved by the appropriate ethics committee and have therefore been performed in accordance with the ethical standards laid down in the 1964 Declaration of Helsinki.

Open Access This article is distributed under the terms of the Creative Commons Attribution License which permits any use, distribution, and reproduction in any medium, provided the original author(s) and the source are credited.

\section{References}

1. McKhann G, Drachmann D, Folstein M, Katzmann R, Price D, Stadlan EM (1984) Clinical diagnosis of Alzheimer's disease. Report of the NINCDS-ADRDA Work Group under the auspices of the Department of Health and Human Services Task Force of Alzheimer's disease. Neurology 34:934-944

2. Biagioni MC, Galvin JE (2011) Using biomarkers to improve detection of Alzheimer's disease. Neurodegener Dis Manag 1:127-139

3. Hesse C, Rosengren L, Andreasen N, Davidsson P, Vanderstichele H, Vanmechelen E, Blennow K (2001) Transient increase in total tau but not phospho-tau in human cerebrospinal fluid after acute stroke. Neurosci Lett 297:187-190

4. Hesse C, Rosengren L, Vanmechelen E, Vanderstichele H, Jensen C, Davidsson P, Blennow K (2000) Cerebrospinal fluid markers for Alzheimer's disease evaluated after acute ischemic stroke. J Alzheimers Dis 2:199-206

5. Lanari A, Parnetti L (2009) Cerebrospinal fluid biomarkers and prediction of conversion in patients with mild cognitive impairment: 4-year follow-up in a routine clinical setting. Sci World J 9:961-966

6. Thaweepoksomboon J, Senanarong V, Poungvarin N, Chakorn T, Siwasariyanon N, Washirutmangkur L, Udompunthuruk S (2011) Assessment of cerebrospinal fluid (CSF) beta-amyloid (1-42), phosphorylated tau (ptau-181) and total Tau protein in patients with Alzheimer's disease (AD) and other dementia at Siriraj Hospital, Thailand. J Med Assoc Thai 94(Suppl 1):S77-S83

7. Ohrfelt A, Andreasson U, Simon A, Zetterberg H, Edman A, Potter W, Holder D, Devanarayan V, Seeburger J, Smith AD, Blennow K, Wallin A (2011) Screening for new biomarkers for subcortical vascular dementia and Alzheimer's disease. Dement Geriatr Cogn Dis Extra 1:31-42

8. Pluta R, Jolkkonen J, Cuzzocrea S, Pedata F, Cechetto D, PopaWagner A (2011) Cognitive impairment with vascular impairment and degeneration. Curr Neurovasc Res 8:342-350

9. Paraskevas GP, Kapaki E, Papageorgiou SG, Kalfakis N, Andreasou E, Zalonis I, Vassilopoulos D (2009) CSF biomarker profile and diagnostic value in vascular dementia. Eur J Neurol 16:205-211

10. Mattsson N, Zetterberg H, Hansson O, Andreasen N, Parnetti L, Jonsson M, Herukka SK, van der Flier WM, Blankenstein MA, Ewers M, Rich K, Kaiser E, Verbeek M, Tsolaki M, Mulugeta E, Rosen E, Aarsland D, Visser PJ, Schroder J, Marcusson J, de Leon M, Hampel H, Scheltens P, Pirttila T, Wallin A, Jonhagen ME, Minthon L, Winblad B, Blennow K (2009) CSF biomarkers and incipient Alzheimer disease in patients with mild cognitive impairment. JAMA 302:385-393

11. Schmidtke K, Hermeneit S (2008) High rate of conversion to Alzheimer's disease in a cohort of amnestic MCI patients. Int Psychogeriatr 20:96-108

12. Hansson O, Zetterberg H, Buchhave P, Londos E, Blennow K, Minthon L (2006) Association between CSF biomarkers and incipient Alzheimer's disease in patients with mild cognitive impairment: a follow-up study. Lancet Neurol 5:228-234

13. Hertze J, Minthon L, Zetterberg H, Vanmechelen E, Blennow K, Hansson O (2010) Evaluation of CSF biomarkers as predictors of Alzheimer's disease: a clinical follow-up study of 4.7 years. J Alzheimers Dis 21:1119-1128

14. Buchhave P, Minthon L, Zetterberg H, Wallin AK, Blennow K, Hansson O (2012) Cerebrospinal fluid levels of beta-amyloid $1-42$, but not of tau, are fully changed already 5 to 10 years before the onset of Alzheimer dementia. Arch Gen Psychiatry 69:98-106

15. Zieren N, Duering M, Peters N, Reyes S, Jouvent E, Herve D, Gschwendtner A, Mewald Y, Opherk C, Chabriat H, Dichgans M (2013) Education modifies the relation of vascular pathology to cognitive function: cognitive reserve in cerebral autosomal dominant arteriopathy with subcortical infarcts and leukoencephalopathy. Neurobiol Aging 34:400-407

16. Pluta R, Ulamek M, Jablonski M (2009) Alzheimer's mechanisms in ischemic brain degeneration. Anat Rec (Hoboken) 292:1863-1881

17. Wen Y, Yang S, Liu R, Simpkins JW (2004) Transient cerebral ischemia induces site-specific hyperphosphorylation of tau protein. Brain Res 1022:30-38

18. Zheng GQ, Wang XM, Wang Y, Wang XT (2010) Tau as a potential novel therapeutic target in ischemic stroke. J Cell Biochem 109:26-29

19. Bielewicz J, Kurzepa J, Czekajska-Chehab E, Stelmasiak Z, Bartosik-Psujek H (2011) Does serum Tau protein predict the outcome of patients with ischemic stroke? J Mol Neurosci 43: 241-245

20. Bitsch A, Horn C, Kemmling Y, Seipelt M, Hellenbrand U, Stiefel M, Ciesielczyk B, Cepek L, Bahn E, Ratzka P, Prange H, Otto M (2002) Serum tau protein level as a marker of axonal damage in acute ischemic stroke. Eur Neurol 47:45-51

21. Wunderlich MT, Lins H, Skalej M, Wallesch CW, Goertler M (2006) Neuron-specific enolase and tau protein as neuro biochemical markers of neuronal damage are related to early clinical course and long-term outcome in acute ischemic stroke. Clin Neurol Neurosurg 108:558-563

22. Gorelick PB, Scuteri A, Black SE, Decarli C, Greenberg SM, Iadecola C, Launer LJ, Laurent S, Lopez OL, Nyenhuis D, Petersen RC, Schneider JA, Tzourio C, Arnett DK, Bennett DA, Chui HC, Higashida RT, Lindquist R, Nilsson PM, Roman GC, Sellke FW, Seshadri S (2011) Vascular contributions to cognitive impairment and dementia: a statement for healthcare professionals from the American heart association/American stroke association. Stroke 42:2672-2713 